\title{
Demanda por gastos públicos locais: evidências dos efeitos de ilusão fiscal no Brasil
}

\author{
Jevuks Matheus Araujo \\ Professor - Universidade Federal da Paraíba (UFPB) \\ Endereço: Cidade Universitária - João Pessoa/PB \\ CEP: 58051-900 - E-mail: jevuks@gmail.com
}

\section{Rozane Bezerra Siqueira}

Professora - Universidade Federal de Pernambuco (UFPE)

Endereço: Av. Prof. Moraes Rego, 1235 - Cidade Universitária - Recife/PE

CEP: 50670-901 - E-mail: rozane_siqueira@yahoo.com.br

Recebido em 14 de dezembro de 2014. Aceito em 10 de julho de 2015.

\section{Resumo}

Além da complexidade e opacidade da tributação, a forte dependência dos municípios brasileiros de transferências federais e estaduais aumenta a chance de ilusão fiscal. Sob o efeito de ilusão fiscal, os contribuintes tendem a subestimar os custos dos bens e serviços providos pelo governo e, portanto, a demandá-los em quantidade maior do que o fariam na ausência de ilusão. O objetivo deste trabalho é estimar os efeitos da ilusão fiscal sobre a demanda por gasto público municipal no Brasil. Com base no modelo do eleitor mediano e usando dados referentes ao ano de 2010 para 5249 municípios, estima-se uma função demanda por bens e serviços públicos locais que inclui variáveis que captam ilusão fiscal. Os resultados evidenciam que ilusão fiscal associada à estrutura tributária e às transferências fiscais pode contribuir para compreensão da expansão gasto público no Brasil.

\section{Palavras-Chave}

Ilusão fiscal. Gasto público local. Transferências intergovernamentais. Estrutura tributária.

\begin{abstract}
In addition to the complexity and opacity of taxation, the strong reliance of Brazilian municipalities on federal and state transfers increases the chance of fiscal illusion. Under fiscal illusion, taxpayers tend to underestimate the costs of the goods and services provided by the government and, thus, to demand them in excess of what would be demanded in the absence of fiscal illusion. The purpose of this study is to estimate the effects of fiscal illusion on the demand for local public spending in Brazil. Based on a median voter model and using data from 2010 for 5249 municipalities, a demand function for local public goods that includes variables to capture fiscal illusion is estimated. The results indicate that fiscal illusion associated to the tax structure and to the fiscal transfers can help to understand the expansion of public spending in Brazil.
\end{abstract}

\section{Keywords}

Fiscal illusion. Local public spending. Intergovernmental transfers. Tax structure.

\section{JEL Classification}

H41. H72. H77.

Estud. Econ., São Paulo, vol.46, n.1, p. 189-219, jan.-mar. 2016 


\section{Introdução}

No final do século XIX, Adolph Wagner estabeleceu que a demanda por gastos públicos tem elasticidade renda maior do que $1 .{ }^{1}$ Desta forma, o crescimento da renda gera uma expansão ainda maior dos gastos públicos. As premissas do que ficou conhecido na literatura como Lei de Wagner são: os bens e serviços públicos não fogem às regras estabelecidas para bens normais; nações mais ricas tornam-se mais complexas e passam a exigir mais ações do Estado, e, por fim, os bens meritórios educação e saúde apresentam características de bens de luxo. Embora não exista um consenso na literatura sobre a validade empírica da lei de Wagner, muitos trabalhos encontraram resultados que dão suporte empírico à lei. ${ }^{2}$

Em meados do século passado, foram propostas e introduzidas nos modelos econômicos novas relações causais para expansão do gasto público. Destaca-se a abordagem da teoria das escolhas públicas que analisa o processo político, a burocracia e outras instituições como variáveis essenciais para compreender a expansão do gasto público. Segundo a abordagem da escolha pública, a oferta de bens públicos está sujeita ao comportamento autointeressado dos políticos e burocratas. Por outro lado, a demanda por bens públicos está associada aos interesses dos eleitores contribuintes. Assim, admitindo-se que os interesses podem ser conflitantes, os gastos públicos não irão necessariamente refletir os desejos dos eleitores contribuintes.

A escolha do orçamento público se dará pela interação de interesses conflitantes e com base em um conjunto de informações assimétricas. Os fazedores de política podem buscar estruturas fiscais (arrecadação e gasto) que distorcem a percepção dos eleitores contribuintes, levando-os sistematicamente a superdimensionar os benefícios do gasto público e a subdimensionar seus custos (Buchanan, 1967 e Oates, 1988). Este fenômeno, conhecido na literatura econômica como ilusão fiscal, vem de forma recorrente sendo utilizado como explicação para expansão dos gastos públicos.

O conceito de ilusão fiscal foi inicialmente desenvolvido por Amilcare Puviani (1903), segundo o qual os governantes possuem capacidade e incentivos para manipular a estrutura fiscal, criando

1 Ver Borcherding (1985); Abizadeh e YousefI (1988); Shelton (2007).

2 Ver Bird (1971); Diamond (1989); Gemmel (1993); Lamartina e Zaghini (2011). 
ilusões otimistas. Os benefícios dos programas governamentais são exagerados e seus verdadeiros custos são ocultados.

Segundo Buchanan (1967), mesmo sob o efeito de ilusão fiscal, as escolhas dos eleitores são racionais e consistentes, ou seja, é possível teorizar sobre o comportamento dos indivíduos. Ainda segundo Buchanan (1967, p.127) "é evidente que as instituições podem criar mecanismos que alterem a percepção dos agentes e que esta questão é digna de estudos". Em geral, os eleitores não têm clareza sobre o que o governo está ou deveria estar fazendo, e frequentemente desconhecem a relação entre as ações governamentais e seus ganhos de utilidade (Downs, 1957). A incerteza restringe a capacidade que o contribuinte possui de relacionar as políticas governamentais com que ele julga ser o melhor para sociedade. Desta forma, o governo possui incentivos para divulgar informações que lhe sejam favoráveis e obstruí-las em caso contrário.

A despeito das limitações de informação, Oates (1988, p.67) afirma que "informação imperfeita não é sinônimo de ilusão fiscal. É uma condição necessária, mas não suficiente, para existência de ilusão fiscal". Oates (1988) segue a linha de argumentação de Buchanan (1967) definindo que a ilusão fiscal dá origem a um viés sistemático nas escolhas fiscais dos contribuintes, entretanto estes agentes se comportam de forma consistente e previsível.

Buchanan (1967) e Tanzi (2011) relacionam vários mecanismos comumente usados pelos governos para criar ou explorar ilusão fiscal. Três das fontes de ilusão mais abortadas na literatura empírica, e que são bastante pertinentes no caso do Brasil, são: a complexidade do sistema tributário, o grau de visibilidade dos tributos e a participação de transferências intergovernamentais no financiamento do gasto público. ${ }^{3}$ Ilusão fiscal permite ao governo ampliar as receitas, sustentando altos níveis de gasto público, e acomodando as demandas dos vários grupos da sociedade com voz política. Além disso, ilusão ajuda o governo a explicar ou justificar os gastos improdutivos arrebatados por grupos de interesse. Desta forma, ilusão fiscal é um importante conceito para entender o crescimento do gasto público (Tanzi, 2011).

O gasto público no Brasil tem crescido consideravelmente. A despesa primária do governo federal passou de $11,1 \%$ do PIB em 1991 para

\footnotetext{
3 Ver Siqueira e Nogueira (2014) para uma relação de outras fontes de ilusão fiscal no Brasil.
} 
17,5\% em 2010. Adicionando as transferências intergovernamentais, o gasto passa de $13,7 \%$ do PIB em 1996 para $21,5 \%$ do PIB em $2010 .{ }^{4}$ A carga tributária brasileira no ano de 2010 foi de 34,19\% do PIB, o que representou uma arrecadação de 1,2 bilhões de reais. ${ }^{5}$ Deste montante, $45 \%$ foram oriundos de tributação indireta.

Com relação à arrecadação por esfera de governo, tem-se a seguinte divisão: $67,45 \%, 26,5 \%$ e $6,05 \%$ respectivamente para governo federal, estadual e municipal. Se olharmos a distribuição da receita disponível, verificamos a seguinte divisão 56,62\%, 25,09\% e 18,29\% respectivamente para governo federal, estadual e municipal. A importância crucial das transferências intergovernamentais no financiamento do gasto público no Brasil reflete o forte desequilíbrio fiscal vertical característico do federalismo brasileiro. A assimetria entre as responsabilidades de gasto e a capacidade de mobilizar recursos é particularmente marcante no caso dos governos municipais, que dependem fortemente de transferências federais e estaduais.

Vários estudos mostram que esse tipo de federalismo - em que uma parte expressiva do gasto público é financiada através de transferências intergovernamentais - está associado a um setor público maior. ${ }^{6}$ Em parte isso se deve ao chamado efeito flypaper, que é o fenômeno observado na literatura empírica que os gastos dos governos locais são mais sensíveis a aumentos nas transferências recebidos de outras esferas de governo do que a aumentos nas rendas privadas locais.

Note-se que o efeito flypaper contraria o "teorema da equivalência ricardiana". Embora sua lógica subjacente não seja clara, o fenômeno é consistente com a teoria da ilusão fiscal. Transferências intergovernamentais criam a ilusão de que os bens e serviços providos pelos governos locais são financiados por não residentes, facilitando a expansão do gasto público. Neste contexto, é surpreendente que tão poucos estudos tenham abordado a questão da ilusão fiscal no Brasil. Siqueira e Nogueira (2014) chama atenção para a relevância do tema. Os autores argumentam que ilusão fiscal pode ajudar a explicar a baixa efetividade da política fiscal brasileira, que combina elevada carga tributária e elevada desigualdade de renda, além de serviços públicos de baixa qualidade.

\footnotetext{
4 Dados extraídos de Rezende (2013).

5 Dados extraídos de Afonso, Soares e Castro (2013).

6 Ver, por exemplo, Stein (1999) e Rodden (2003).
} 
Silva e Siqueira (2014) testa empiricamente a influência de ilusão fiscal sobre o gasto público no Brasil. O foco do estudo é a despesa primária do governo federal, no período de 1990 a 2011. Utilizando um modelo econométrico de correção de erros (ECM), os autores encontram evidências de que quanto mais visível a tributação menor o gasto federal, conforme previsto pela teoria da ilusão fiscal. Embora apresente limitações de disponibilidade de dados para o método adotado, esse trabalho representa o primeiro esforço para mensurar os efeitos da ilusão fiscal sobre a expansão do setor público brasileiro.

Mendes (2005) usa dados de corte transversal dos municípios brasileiros, referentes ao ano de 1996, para analisar o problema da captura de transferências fiscais por burocratas e políticos do governo local. O artigo mostra que a captura cresce com o aumento da participação de transferências incondicionais nas receitas municipais. $\mathrm{O}$ autor ressalta a coerência deste resultado com a hipótese de que transferências intergovernamentais são fontes de ilusão fiscal.

Guedes e Gasparini (2007) estudam a descentralização fiscal ocorrida no Brasil e sua relação com o tamanho do governo (razão entre gasto público e PIB), usando dados para os municípios no período de 1998 a 2001. O estudo cita apenas de forma muito superficial o efeito da ilusão fiscal sobre o crescimento da razão entre gasto público e PIB. Existem outros trabalhos que exploram temas correlatos, mas não abordam de fato o fenômeno da ilusão fiscal no Brasil. ${ }^{7}$

O objetivo deste trabalho é analisar a influência de ilusão fiscal sobre a demanda por gasto público municipal no Brasil. Tomando como base o modelo do eleitor mediano e usando dados referentes ao ano de 2010 para 5249 municípios, estima-se uma função demanda por bens públicos locais que contém variáveis para captar os efeitos ilusórios associados à estrutura tributária e às transferências intergovernamentais.

Além desta introdução, este trabalho está composto por mais seis seções. Na próxima seção é discutida a estrutura fiscal dos municípios no Brasil. A seção 3 descreve a formalização do modelo do eleitor mediano. Na seção 4 é feita descrição dos dados. Na seção 5 é

7 Cossio e Carvalho (2001), Mattos, Rocha e Arvate (2011) e Sakurai (2013) analisam o efeito flypaper no Brasil. Mendes e Sousa (2006) e Meneses, Saiani e Zoghbi (2011) analisam a demanda por bens públicos locais utilizando o modelo do eleitor mediano. 
formalizada a modelagem empírica. A seção 6 discute os resultados. Por fim, a seção 7 resume as conclusões do trabalho.

\section{Estrutura fiscal dos municípios brasileiros}

Esta seção descreve a estrutura de financiamento do gasto público municipal e procura identificar possíveis fontes de ilusão. Indicadores das fontes ilusão fiscal são então propostos.

\subsection{Estrutura da receita}

A Constituição 1988 aumentou a participação dos Estados e Municípios na arrecadação de receitas e no gasto público no Brasil. O processo de descentralização fiscal também permitiu uma maior autonomia dos Governos Municipais e Estaduais na execução das políticas públicas (Varsano (1996); Afonso e Araújo (2001)). Segundo Afonso e Araújo (2001, p.2), "a descentralização dos recursos tributários, promovida pela Constituição de 1988, foi acima de tudo um movimento de municipalização da receita".

A tabela abaixo apresenta os dados que caracterizam o processo de municipalização da receita. Observa-se que entre 1980 e 2010, a carga tributária no Brasil cresceu aproximadamente 10 pontos percentuais em relação ao PIB. Neste mesmo período houve uma redução da participação do Governo Federal na arrecadação total e na receita disponível. Esta redução é (em parte) consequência da perda de base tributária e do aumento das transferências intergovernamentais instituídas pela Constituição de 1988.

Na Tabela 1, observa-se que os Estados aumentaram a sua participação na arrecadação total e na receita disponível. Entretanto, os Estados não são mais beneficiários líquidos das transferências. Em 1980, os Estados apresentavam uma participação na receita disponível maior do que na arrecadação total, ou seja, eles eram favorecidos pelas transferências intergovernamentais. Após a Constituição de 1988, os Estados passam a ter uma participação na receita disponível menor do que sua participação na arrecadação total. 
Tabela 1 - Participação dos Níveis de Governo na Arrecadação e na Receita Disponível

\begin{tabular}{|c|c|c|c|}
\hline Descrição & 1980 & 1995 & 2010 \\
\hline Carga Tributária (\% do PIB) & $24,50 \%$ & $29,41 \%$ & $34,19 \%$ \\
\hline \multicolumn{4}{|c|}{ Participação na Arrecadação Total } \\
\hline União & $74,70 \%$ & $66,0 \%$ & $67,45 \%$ \\
\hline Estados & $21,60 \%$ & $28,60 \%$ & $26,5 \%$ \\
\hline Municípios & $3,70 \%$ & $5,40 \%$ & $6,05 \%$ \\
\hline \multicolumn{4}{|c|}{ Participação na Receita Disponível } \\
\hline União & $68,20 \%$ & $56,20 \%$ & $56,62 \%$ \\
\hline Estados & $23,30 \%$ & $27,20 \%$ & $25,09 \%$ \\
\hline Municípios & $8,50 \%$ & $16,60 \%$ & $18,29 \%$ \\
\hline
\end{tabular}

Fonte: Varsano et al. (1998) e Afonso (2013).

Os dados demonstram um forte aumento na participação dos Municípios na receita disponível e na arrecadação total. Sendo o Município o único beneficiário líquido dos mecanismos de transferências intergovernamentais. A participação dos Municípios na receita disponível cresceu mais que o dobro na comparação entre o ano de 1980 e o ano de 2010. Em uma apreciação mais detalhada da receita tributária municipal para o ano de 2010 (Tabela 2), observa-se que o Imposto Sobre Serviços (ISS) é o principal componente da receita própria $^{8}$ dos municípios, representando $9,5 \%$ da receita corrente, e o Imposto sobre Propriedade Territorial Urbana (IPTU) representa $5 \%$ da receita corrente.

Segundo os dados da Secretária do Tesouro Nacional (STN) para o ano 2010, todos os 5.422 municípios da amostra apresentaram algum tipo de receita tributária. No conjunto completo dos dados, apenas 80 municípios não apresentaram receita de IPTU, e apenas 12 não apresentaram receita de ISS. Verifica-se também que em 86,3\% dos municípios a receita de ISS é maior do que a receita de IPTU.

8 A Receita Própria é aquela diretamente arrecadada composta por receita tributária, receita de contribuições, receita patrimonial, receita de serviços e receita industrial. 
Tabela 2 - Composição da Receita Corrente dos Municípios no Ano de 2010 (valores em \%)

\begin{tabular}{|lrrr|}
\hline Receitas Correntes & Todos os Municípios & $\begin{array}{c}\text { Municípios com } \\
\text { até } 50 \text { mil habitantes }\end{array}$ & $\begin{array}{c}\text { Municípios com } \\
\text { mais de } 50 \text { mil } \\
\text { habitantes }\end{array}$ \\
\hline Próprias & 25.90 & 11.55 & 34.17 \\
\hline IPTU & 5.00 & 1.39 & 6.72 \\
\hline ISS & 9.55 & 3.36 & 12.49 \\
\hline ITBI & 1.68 & 0.72 & 2.14 \\
\hline Taxas & 1.36 & 0.69 & 1.67 \\
\hline Contribuição de Melhorias & 0.05 & 0.07 & 0.04 \\
\hline Outras & 8.25 & 5.30 & 11.12 \\
\hline Transferências Correntes & 69.22 & 84.79 & 59.89 \\
\hline FPM & 16.30 & 31.12 & 9.26 \\
\hline ICMS & 20.32 & 19.44 & 20.74 \\
\hline IPVA & 3.28 & 1.60 & 4.08 \\
\hline Outras Transferências & 29.31 & 32.62 & 25.81 \\
\hline Outras Receitas Correntes & 4.88 & 3.66 & 5.94 \\
\hline Total & 100.00 & 100.00 & 100.00
\end{tabular}

Fonte: Elaboração Própria a partir dos dados da Secretária do Tesouro Nacional (STN).

Para os municípios com população de até 50 mil habitantes $(89 \%$ dos municípios da amostra) a receita própria representa apenas $11,55 \%$ da receita corrente. Enquanto que nos municípios com população superior a 50 mil habitantes, a receita própria representa $34,17 \%$ da receita corrente municipal. Em $26 \%$ dos municípios com população superior a 50 mil habitantes a arrecadação de IPTU e ISS (somadas) é superior à transferência recebida do Fundo de Participação dos Municípios (FPM). ${ }^{9}$

Com relação à participação da receita de transferências correntes observa-se que, para amostra com todos os municípios, a receita de transferência da cota parte do Imposto Sobre Circulação de Mercadorias e Serviços (ICMS) representa 20,32\% e a receita do FPM representa 16,30\%. Entretanto, em $81 \%$ dos municípios a receita de FPM é maior do que a receita de ICMS.

9 O FPM é uma transferência constitucional da União para os municípios. A origem dos recursos é fixada em 23,5\% da arrecadação do Imposto de Renda (IR) e do Imposto sobre Produtos Industrializados (IPI). 
Para os municípios com população de até 50 mil habitantes, as transferências correntes representam $84,79 \%$ da receita corrente. Enquanto que nos municípios com população superior a 50 mil habitantes, as transferências correntes representam 59,89\% da receita corrente municipal. Temos que em $96 \%$ dos municípios, com população de até 50 mil habitantes, a receita recebida do FPM é maior do que receita própria e em apenas $2 \%$, destes municípios, a receita tributária é maior do que a receita recebida do FPM.

\subsection{Indicadores de ilusão fiscal nos municípios}

Seguindo a maior parte da literatura empírica, o indicador escolhido para medir o grau de complexidade da receita tributária é o índice de Herfindahl (HH). ${ }^{10} \mathrm{O}$ cálculo do índice se dá pela seguinte equação:

$$
H H=\sum_{i=1}^{n} T_{i}^{2}
$$

Em que $T_{i}$ é a participação do tributo i na receita tributária (RT) e n é número de tributos.

As fontes de receita tributária consideradas foram: IPTU, ITBI, ISS, Taxas e Contribuição de Melhoria (CM). Reescrevendo a Equação (1) temos:

$$
H H=\frac{I P T U^{2}+I T B I^{2}+I S S^{2}+\operatorname{Taxas}^{2}+C M^{2}}{R T^{2}}
$$

A Tabela 2.3 apresenta um resumo da estatística descritiva da complexidade da receita dos municípios calculada pelo índice Herfindahl. Para uma amostra completa de 5421 municípios (coluna 2), observamos que os valores apresentam uma média de 0,51. Os valores do desvio padrão, assimetria e curtose demonstram que os dados apresentam uma baixa dispersão e com uma distribuição concentrada a esquerda, ou seja, mais próxima de zero. Pelos dados

\footnotetext{
10 Índice de concentração que varia de 0 a 1 . Quanto maior o índice maior a concentração, logo menor é a complexidade.
} 
temos que 25\% dos municípios (terceiro quartil) apresentam índice de concentração maior ou igual 0,67.

Como os municípios brasileiros são em sua maioria municípios pequenos, com menos de 15 mil habitantes, estratificamos os dados em amostras por tamanho de município. O resultado apresentado na Tabela 3 (última linha) mostra que não foi identificado grau de associação linear entre o tamanho da população e o índice $\mathrm{HH}$. Entretanto, os demais resultados na tabela mostram que municípios com mais de 50 mil habitantes possuem, em média, um maior grau de complexidade da receita. Os municípios com menos de 50 mil habitantes apresentam uma maior dispersão dos dados com uma amplitude total de 0,79 e um desvio padrão em torno de 0,22.

Tabela 3 - Estatística Descritiva do Índice de Complexidade

\begin{tabular}{l|r|r|r|r|r|r}
\hline \multirow{2}{*}{ Estatística } & Todos os & \multicolumn{6}{|c}{ Habitantes (N) em Milhares } \\
\cline { 5 - 7 } & Municípios & Até 5 & $5<\mathrm{N} \leq 15$ & $15<\mathrm{N} \leq 50$ & $50<\mathrm{N} \leq 150$ & $\mathrm{~N}>150$ \\
\hline Média & 0,51 & 0,51 & 0,52 & 0,52 & 0,44 & 0,41 \\
Desvio Padrão & 0,22 & 0,23 & 0,22 & 0,21 & 0,16 & 0,11 \\
\hline Mínimo & 0,21 & 0,21 & 0,21 & 0,21 & 0,22 & 0,25 \\
Máximo & 1,00 & 1,00 & 1,00 & 1,00 & 0,99 & 0,92 \\
Mediana & 0,44 & 0,42 & 0,45 & 0,46 & 0,38 & 0,38 \\
$1^{0}$ Quartil & 0,32 & --- & --- & --- & --- & -- \\
$3^{0}$ Quartil & 0,67 & --- & --- & --- & -- & - \\
Assimetria & 0,68 & 0,65 & 0,56 & 0,62 & 1,18 & 1,61 \\
\hline Curtose & 2,20 & 2,05 & 1,98 & 2,17 & 3,65 & 6,22 \\
\hline Observações & 5421 & 1269 & 2036 & 1518 & 424 & 174 \\
\hline
\end{tabular}

Teste de Correlação

Teste $\mathrm{H}_{0}$ : Tamanho da população e o índice de complexidade são independentes

Coeficiente de correlação de Spearman

$-0,0165$

Prob $>|t|$

0,2235

Número de observações

5421

Fonte: Elaboração própria a partir dos dados da pesquisa.

Os dados municipais revelam que aproximadamente 15\% dos municípios apresentam um índice de complexidade maior ou igual a 0,8 (arrecadação menos fragmentada) e que aproximadamente 17\% dos municípios apresentam um índice de complexidade inferior ou igual a 0,3 (arrecadação mais fragmentada). Outro aspecto do financiamento do gasto público municipal a ser analisado é a visibilidade dos tributos, representada aqui pela participação dos tributos diretos na 
receita tributária. Assim, supõe-se que quanto maior a participação dos tributos diretos, maior o grau de visibilidade do sistema tributário. Mensuramos a visibilidade pela seguinte razão:

$$
\text { visibilidade }=\frac{I P T U+I T B I+\text { Taxas }}{R T}
$$

O Imposto sobre Propriedade Predial e Territorial Urbana (IPTU) e o Imposto sobre a Transmissão Intervivos de Bens Imóveis (ITBI) são os impostos diretos de competência dos municípios. As Taxas são tributos vinculados à ação do Estado, e, no caso dos municípios, são referentes ao exercício do Poder de Polícia e à Prestação de Serviços (serviços ambientais, iluminação pública, coleta de lixo, etc.).

A Tabela 4 apresenta o resumo estatístico do grau de visibilidade do sistema tributário dos municípios. Para uma amostra de 5421 municípios (coluna 2), observa-se que os dados se distribuem em torno de um valor médio de $0.40 \mathrm{com}$ uma alta dispersão. Temos que $25 \%$ dos municípios apresentam grau de visibilidade menor do 0,17 $\left(1^{0}\right.$ Quartil). Estratificamos a amostra por tamanho do município. Os resultados demonstram que não há associação linear entre o tamanho da população e o grau de visibilidade tributária. Entretanto, os demais resultados da tabela mostram que os municípios maiores apresentam, em média, um maior grau de visibilidade tributária.

Tabela 4 - Estatística Descritiva do Grau de Visibilidade da Receita Tributária

\begin{tabular}{|c|c|c|c|c|c|c|}
\hline \multirow{2}{*}{ Estatística } & \multirow{2}{*}{$\begin{array}{c}\text { Todos os } \\
\text { Municípios }\end{array}$} & \multicolumn{5}{|c|}{ Habitantes (N) em Milhares } \\
\hline & & Até 5 & $5<\mathrm{N} \leq 15$ & $15<\mathrm{N} \leq 50$ & $50<\mathrm{N} \leq 150$ & $\mathrm{~N}>150$ \\
\hline Média & 0,40 & 0,42 & 0,39 & 0,37 & 0,44 & 0,47 \\
\hline Desvio Padrão & 0,24 & 0,26 & 0,25 & 0,23 & 0,20 & 0,15 \\
\hline Mínimo & 0 & 0 & 0 & 0 & 0 & 0,03 \\
\hline Máximo & 1 & 1 & 1 & 1 & 0,91 & 0,92 \\
\hline Mediana & 0,40 & 0,43 & 0,37 & 0,36 & 0,47 & 0,49 \\
\hline $1^{0}$ Quartil & 0,17 & -- & -- & $\cdots$ & $\cdots$ & $\cdots$ \\
\hline $3^{0}$ Quartil & 0,61 & -- & -- & $\cdots$ & -- & $\cdots$ \\
\hline Assimetria & 0,07 & 0,01 & 0,14 & 0,14 & $-0,16$ & $-0,22$ \\
\hline Curtose & 1,18 & 1,71 & 1,76 & 1,9 & 2,16 & 3,03 \\
\hline Observações & 5421 & 1269 & 2036 & 1518 & 424 & 174 \\
\hline \multicolumn{7}{|c|}{ Teste de Correlação } \\
\hline \multicolumn{7}{|c|}{ Teste H0: Tamanho da população e o índice de complexidade são independentes } \\
\hline \multicolumn{6}{|c|}{ Coeficiente de correlação de Spearman } & $-0,0161$ \\
\hline \multicolumn{6}{|l|}{ Prob $>|t|$} & 0,2346 \\
\hline \multicolumn{6}{|c|}{ Número de observações } & 5421 \\
\hline
\end{tabular}

Fonte: Elaboração própria a partir dos dados da pesquisa. 
Observa-se que os municípios com mais de 50 mil habitantes apresentam, em média, um grau de visibilidade de 0,45. Ou seja, em média, $45 \%$ da receita tributária destes municípios é oriunda de tributos diretos, considerados mais visíveis. No caso dos municípios com população até 50 mil habitantes este valor médio cai para $39 \%$. Assim, como os dados do índice de complexidade, o grau de visibilidade calculado apresenta uma elevada dispersão entre os municípios. Com uma amplitude interquartil de 0,44. Para municípios com mais 50 mil, habitantes esta amplitude é de 0,29 , e para os municípios com menos de 50 mil habitantes é de 0,45.

Outro indicador que nos remete à presença da ilusão fiscal é a participação das transferências não condicionadas no orçamento municipal. Como indicado na teoria, uma maior participação relativa destas transferências no financiamento do gasto público local reduz a percepção dos eleitores dos reais custos do provimento de bens e serviços públicos.

As transferências não condicionadas recebidas pelo município e consideradas neste trabalho são: ${ }^{11}$ o Fundo de Participação Municipal (FPM); a cota IOF-ouro, ${ }^{12}$ a cota do IPVA ${ }^{13}$ e a cota do ICMS. ${ }^{14}$ As transferências não condicionadas representam, em média, 55,2\% da receita corrente dos municípios ${ }^{15}$. O Gráfico 1 apresenta a participação individual, em média, de cada uma das transferências citadas na receita corrente municipal. Observa-se que o FPM representa em média $36,1 \%$ da receita corrente e que a cota parte do ICMS tem em média uma participação de $17,5 \%$.

Esta distribuição muda à medida que alteramos a amostra por tamanho de município. Quando consideramos apenas os municípios acima de 50 mil habitantes ${ }^{16}$ (Gráfico 2), observa-se que as transferências incondicionais representam em média $39,5 \%$ da receita corrente dos municípios.

${ }^{11}$ Segundo classificação dada por Afonso, Soares e Castro (2013).

12 Imposto sobre operações financeiras ligadas ao ouro de competência da União. Os recursos arrecadados são, em sua totalidade, transferidos para os Estados e Municípios. Aos Municípios são destinados $70 \%$ do total arrecadado.

${ }^{13}$ Imposto sobre a Propriedade de Veículos Automotores (IPVA) de competência dos Estados que transferem $50 \%$ dos recursos arrecadados para os municípios.

${ }^{14}$ Imposto sobre Circulação de Mercadorias e Serviços (ICMS) de competência dos Estados que transferem $25 \%$ dos recursos arrecadados para os municípios.

${ }^{15} \mathrm{O}$ cálculo foi realizado observando a participação percentual em cada município e depois calculando a média da participação percentual.

${ }^{16}$ Esta amostra representa 599 municípios. 
A queda na participação se dá pela redução acentuada do $\mathrm{FPM},{ }^{17}$ que para este estrato da amostra representa apenas $17,6 \%$ das receitas correntes. Entretanto, estes municípios apresentam uma maior participação das transferências incondicionais que possuem um caráter devolutivo (cota ICMS e cota IPVA). Somadas, estas transferências representam em média $21,8 \%$ da receita corrente dos municípios com mais de 50 mil habitantes.

No Gráfico 3, temos os municípios com menos de 15 mil habitantes. ${ }^{18}$ Observa-se que as transferências incondicionais representam em média $61,3 \%$ das receitas correntes destes municípios. A participação do FPM em média é de 42,2\% e da cota do ICMS é de 17,9\%.

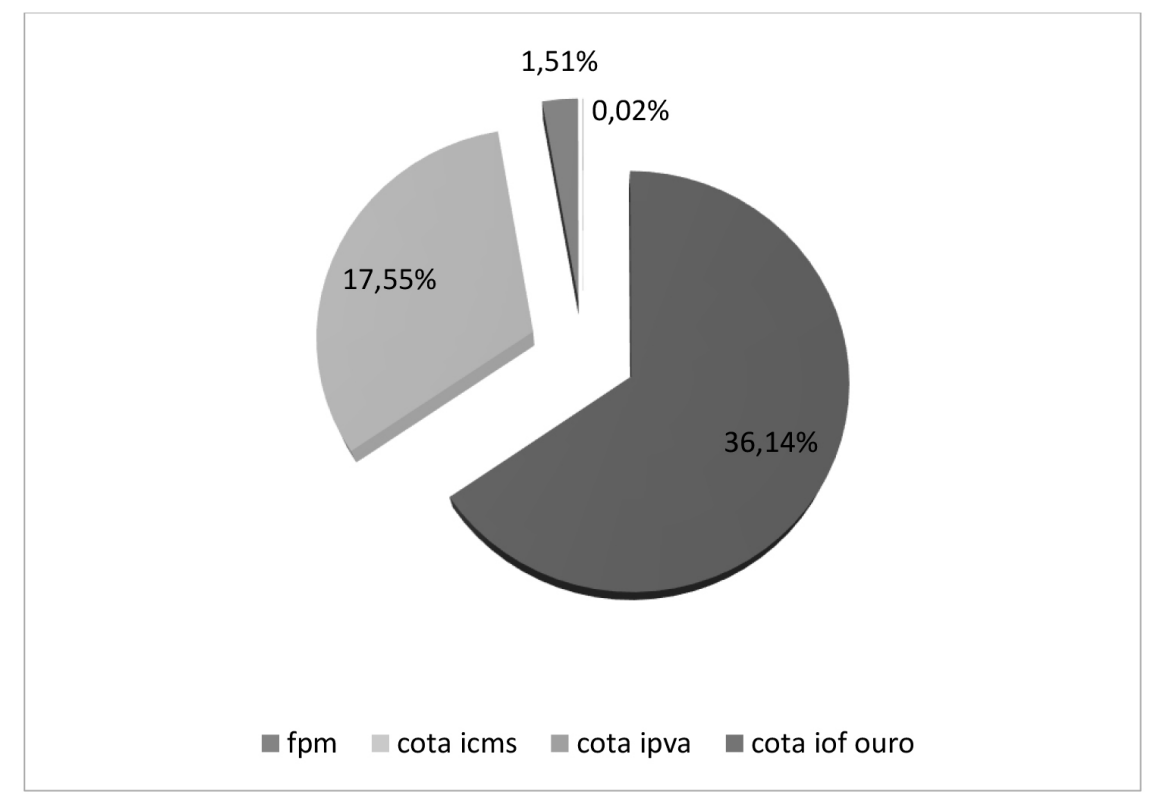

Gráfico 1 - Participação (\%) Média das Transferências não Condicionadas na Receita Corrente.

Fonte: Elaboração própria a partir dos dados da pesquisa.

\footnotetext{
${ }^{17}$ O FPM possui um caráter redistributivo e sua divisão é feita com base em fatores populacionais. Desta forma, é natural que municípios maiores tenham redução na participação do FPM em sua receita.

${ }^{18}$ Esta amostra representa 3305 municípios.
} 


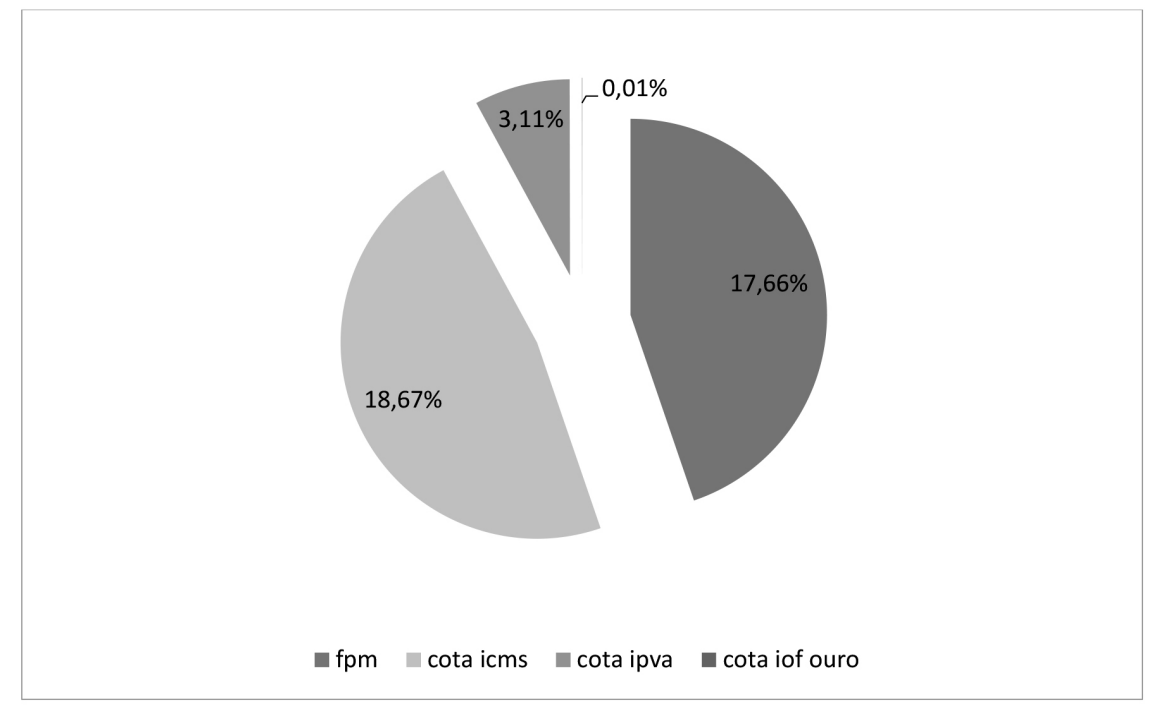

Gráfico 2 - Participação (\%) Média das Transferências não Condicionadas na Receita Corrente dos Municípios com mais de 50 mil habitantes.

Fonte: Elaboração própria a partir dos dados da pesquisa.

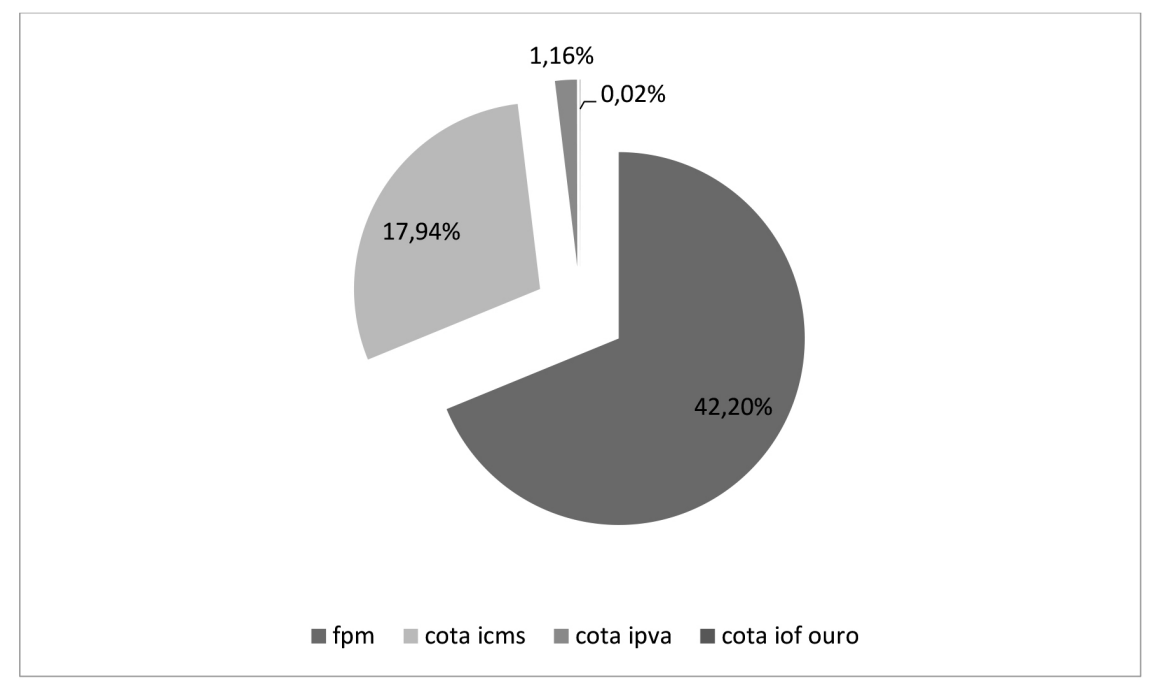

Gráfico 3 - Participação (\%) Média das Transferências não Condicionadas na Receita Corrente dos Municípios com Menos de 15 Mil Habitantes.

Fonte: Elaboração própria a partir dos dados da pesquisa. 
É evidente que nos municípios menores há uma maior participação das transferências incondicionais na receita corrente. Entretanto, não é possível desprezar a participação destas transferências na receita municípios maiores. A elevada participação destas transferências permite aos governantes um maior poder discricionário na alocação dos recursos. Isto possibilita direcionar os gastos de forma a acomodar os interesses daqueles grupos que dão sustentação ao governo.

Observa-se que os indicadores fiscais descritos acima não permitem uma caracterização homogênea dos municípios. Ou seja, embora as regras fiscais sejam as mesmas, os municípios apresentam claras distinções quanto à complexidade da receita, à visibilidade tributária e à importância das transferências lump sum. Desta forma, estes indicadores permitem testar empiricamente a existência e os possíveis efeitos de ilusão fiscal sobre o tamanho do gasto público nos municípios brasileiros.

\section{Formalização do modelo do eleitor mediano}

Borcherding e Deacon (1972) e Bergstrom e Goodman (1973) estabelecem uma modelagem matemática simples que permite estimar demanda por bens públicos locais, usando o arcabouço teórico da escolha pública. A partir da função utilidade do eleitor mediano (identificado como o eleitor de renda mediana), dada por $U_{m}(x, g)$, temos que:

$$
\text { Max } U_{m}(x, g) \text { s. } a\left\{\begin{array}{l}
y_{m}=t b_{m}+x \\
C_{G} G=t B \\
g=\frac{G}{N^{\lambda}}
\end{array}\right.
$$

Em que $\mathrm{x}$ mede a quantidade de consumo do bem privado, e serve como numerário; g é a quantidade de bens públicos ofertados. A Equação 4 representa a restrição orçamentária do eleitor mediano, em que $y_{m}$ e $b_{m}$ são respectivamente a renda e a base tributária do eleitor mediano. A Equação 5 descreve a restrição orçamentária do governo, em que $\mathrm{G}$ é a produção total de bens público, $\mathrm{C}_{\mathrm{G}}$ é custo unitário de cada bem, $\mathrm{C}_{\mathrm{G}} \mathrm{G}$ é gasto público total, t é a alíquota de 
imposto e B reúne todas as bases tributárias. Na Equação 6 temos que $N$ é o tamanho da população e $\lambda$ denota o parâmetro do congestionamento. Se $\lambda=1$, temos que o bem é privado e não há economia de escala para comunidade; caso $\lambda=0$ tem-se caracterizado um bem público puro. Se $\lambda>1$, temos alto congestionamento, e se $0<\lambda<1$ indica que há economias de escala apesar do bem apresentar características de um bem público e características de um bem privado.

Substituindo 6 em 5 temos:

$$
C_{G} g N^{\lambda}=t B \text { ou } t=\frac{C_{G} g N^{\lambda}}{B}
$$

Substituindo 7 em 4 temos:

$$
\frac{C_{G} g N^{\lambda}}{B} b_{m}+x
$$

Encontrando a taxa marginal de substituição entre o consumo do privado e a oferta de bens públicos:

$$
T M S_{x, g}=-\frac{\frac{\partial U_{m}}{\partial g}}{\frac{\partial U_{m}}{\partial x}}=\frac{b_{m}}{b} N^{(\lambda-1)} C_{G}=P_{g}
$$

Temos que b é a base tributária média e Pg é o preço do imposto (tax price), ou seja, o preço de se adquirir uma unidade a mais do bem público. O preço do imposto leva em consideração o tax share $\left(\frac{b_{m}}{b}\right)$, o custo unitário do bem público $\mathrm{C}_{\mathrm{G}}$, o tamanho da população $\mathrm{N}$ e o efeito congestionamento $\lambda$.

Considerando que a função demanda $\left(g=f\left(y_{m}, P_{g}\right)\right)$, pode ser representada por uma função com elasticidades preço e renda constantes, temos:

$$
g=\alpha P_{g}^{\beta_{1}} y_{m}^{\beta_{2}}
$$

Reescrevendo em termos de G, temos:

$$
G=g N^{\lambda}=\alpha P_{g}^{\beta_{1}} y_{m}^{\beta_{2}} N^{\lambda}
$$


Se multiplicarmos ambos os lados da Equação 10 por $\mathrm{P}_{\mathrm{g}}$ encontraremos uma função estimável para gasto público (E).

$$
E=P_{g} G=P_{g} g N^{\lambda}=\alpha P_{g}^{\beta_{1}+1} y_{m}^{\beta_{2}} N^{\lambda}
$$

Esta função tem sido exaustivamente utilizada na literatura para analisar a elasticidade preço da demanda por bens públicos e o efeito congestionamento. Entretanto, abordagem do eleitor mediano considera que o eleitor-contribuinte conhece o custo ou preço do imposto. Nos trabalhos sobre ilusão fiscal é incorporado ao preço do imposto um parâmetro de percepção, no qual estão presentes certas características do sistema fiscal.

\subsection{A ilusão fiscal em nivel local ${ }^{19}$}

A demanda por bens públicos locais pelo eleitor contribuinte pode ser descrita como:

$$
E_{i}=P_{g_{i}} G=P_{g_{i}} g_{i} N^{\lambda}=\alpha P_{g_{i}}^{\beta_{1}+1} y_{i}^{\beta_{2}} N^{\lambda} Z^{\beta_{3}}
$$

Em que i representa o eleitor contribuinte; $\mathrm{E}_{\mathrm{i}}$ é a demanda por bens públicos locais (gastos públicos locais); $\mathrm{g}_{\mathrm{i}}$ é o consumo de bens públicos; $y_{\mathrm{i}}$ é a renda do eleitor mediano; $\mathrm{P}_{\mathrm{gi}}$ é o preço do imposto e $\mathrm{Z}$ é um vetor de outras variáveis explicativas.

Reescrevendo 13 em termos per capita, temos:

$$
e_{i}=\frac{E_{i}}{N}=\frac{P_{g_{i}} G}{N}=P_{g_{i}} g_{i} N^{\lambda-1}=\alpha P_{g_{i}}^{\beta_{1}+1} y_{i}^{\beta_{2}} N^{\lambda-1} Z^{\beta_{3}}
$$

O preço do imposto é definido como:

$$
P_{g_{i}}=\frac{b_{m}}{b} N^{(\lambda-1)} C_{G}
$$

19 Modelo adaptado do trabalho de Gemmell, Morrissey e Pinar (2002). 
Em que: $\left(\frac{b_{m}}{b}\right)$ é a fração do imposto paga por i; $C_{G}$ é custo unitário de g, $\mathrm{N}$ é a população e $\lambda$ é o grau de publicidade do bem (mede o efeito congestionamento).

Substituindo 15 em 14 temos:

$$
E_{i}=\alpha\left[\frac{b_{m}}{b} N^{(\lambda-1)} C_{G}\right]^{\beta_{1}+1} y_{i}^{\beta_{2}} N^{\lambda-1} Z^{\beta_{3}}
$$

Assumindo que o custo unitário seja igual a 1, temos que:

$$
P_{g_{i}}=\frac{b_{m}}{b} N^{(\lambda-1)}
$$

Entretanto, temos que os eleitores contribuintes estão sujeitos a ilusão fiscal. Logo, a demanda por bens públicos depende da percepção que eles possuem sobre o preço do imposto. O preço do imposto percebido pode ser definido como:

$$
\hat{P}_{g i}=\Pi_{\mathrm{i}} P_{g i}
$$

Em que: П é o parâmetro de percepção do indivíduo i.

O П pode se definido como uma função de características da estrutura fiscal local.

$$
\Pi_{\mathrm{i}}=(\text { TRANSFERÊNCIA })_{\mathrm{i}}^{\pi_{1}}(\text { SIMPLICIDADE })_{\mathrm{i}}^{\pi_{2}}
$$

Em que: TRANSFERÊNCIA representa as transferências lump sum per capita recebidas da União e dos Estados; SIMPLICIDADE é dada pelo grau de concentração da receita medido pelo índice Herfinhahl ponderado pelo grau de visibilidade da receita mensurado pela participação dos impostos diretos na arrecadação total. ${ }^{20}$

${ }^{20}$ Embora, a concentração na arrecadação tributária nos remeta à simplicidade, em alguns casos ela pode ocorrer via tributos que aumentam a ilusão fiscal. Desta forma, a ponderação permite reduzir um possível viés de concentração da receita por meio de tributação indireta. O índice de complexidade ponderado pela visibilidade ganha em qualidade de informação. Por exemplo, dois municípios A e B que apresentam o mesmo grau de concentração, suponham de 0,7 , mas com o grau de visibilidade diferente, suponham A com visibilidade de 0,1 e 


\section{Descrição dos dados}

O propósito deste trabalho é testar empiricamente o efeito da ilusão fiscal sobre a demanda por bens públicos locais nos municípios brasileiros. Os dados utilizados são referentes aos municípios brasileiros no ano de 2010, obtidos a partir do Censo 2010, do Atlas do Desenvolvimento Humano 2013 (dados referentes ao ano de 2010) e do banco de dados da Secretária do Tesouro Nacional. Com a unificação dos dados das diferentes fontes foi possível montar um conjunto de informações para uma amostra de 5279 municípios que correspondem a $95 \%$ dos municípios brasileiros.

As variáveis utilizadas estão descritas no quadro abaixo. Ressaltamos algumas dificuldades na definição e construção de variáveis importantes do modelo. Como por exemplo, o tax share, pois não temos informação sobre o valor das propriedades do eleitor mediano. Neste trabalho, será utilizada a razão entre a renda mediana e média como proxy para o tax share do eleitor mediano. Se renda mediana for menor do que a renda média o eleitor mediano pagará menos imposto. ${ }^{21}$ Os dados demonstraram que em 95\% dos municípios da amostra a renda mediana é menor do que a renda média. Esta relação foi utilizada por Mendes e Sousa (2005) e por Meneses, Saiani e Zoghbi (2011).

B com 0,2. Estes municípios terão respectivamente os níveis de simplicidade de 0,07 e 0,14. Assim, a ponderação busca qualificar o nível de simplicidade da arrecadação tributária. Algo semelhante é feito nos trabalhos de Turnbull (1998) e Pommerehne e Schneider (1978).

${ }^{21}$ Assumindo um tributo uniforme o preço do imposto será $\frac{\mathbf{1}}{\boldsymbol{N}}$ e à dívida tributária é $\frac{G}{N}$. Admitindo que a renda média seja $\overline{\boldsymbol{Y}}$ a renda total será $N \overline{\boldsymbol{Y}}$ e sendo $\boldsymbol{t}$ a quantidade de imposto a ser pago. Temos que $G=t N \overline{\boldsymbol{Y}}$ e $t=\frac{G}{N \bar{Y}}$. Desta forma, uma pessoa de renda $\boldsymbol{Y}_{\boldsymbol{i}}$ paga $t Y_{i}=\frac{G Y_{i}}{N \bar{Y}}$. As-

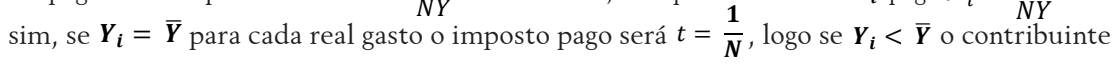
de renda média pagará mais imposto. 
Quadro 1. Descrição das Variáveis.

\begin{tabular}{|c|c|}
\hline Variável Dependente & Descrição \\
\hline $\begin{array}{l}\text { Gasto público municipal } \\
\text { per capita }\left(e_{i}\right)\end{array}$ & $\begin{array}{l}\text { Reflete a procura por bens públicos locais. Neste trabalho será } \\
\text { representado pela despesa corrente. }\end{array}$ \\
\hline Variáveis Explicativas & Descrição \\
\hline Renda mediana $\left(y_{i}\right)$ & $\begin{array}{l}\text { Espera-se que está variável possua um efeito positivo sobre gasto } \\
\text { público. No modelo tradicional do eleitor mediano, esta variável é } \\
\text { representada pela soma da renda mediana com a fração do im- } \\
\text { posto multiplicado pelas transferências per capita. No modelo com } \\
\text { ilusão fiscal desagregamos a renda mediana das transferências. } \\
\text { Desta forma, é possível verificar a existência da ilusão fiscal mani- } \\
\text { festada no efeito flypaper. }\end{array}$ \\
\hline Tax share $\left(\frac{\mathrm{b}_{\mathrm{m}}}{\mathrm{b}}\right)$ & $\begin{array}{l}\text { É dada pela razão entre renda mediana e renda média. Mede a } \\
\text { fração do imposto paga pelo eleitor mediano. } \\
\text { Mede a sensibilidade da demanda em relação ao preço dos bens } \\
\text { públicos. Espera-se um coeficiente com sinal negativo. }\end{array}$ \\
\hline População (Ni $)$ & $\begin{array}{l}\text { Tamanho da população do município. A relação de forma geral é } \\
\text { positiva, entretanto uma relação negativa pode indicar ganho de } \\
\text { escala. } \\
\text { A combinação com o coeficiente da variável }\left(\frac{b_{m}}{b}\right) \text { obtém o grau de } \\
\text { publicidade (congestionamento) dos gastos. }\end{array}$ \\
\hline $\begin{array}{l}\text { Transferências } \\
\text { per capita (transferências }{ }_{i} \text { ) }\end{array}$ & $\begin{array}{l}\text { Transferências não condicionadas (lump sum) para o município. } \\
\text { Espera-se uma relação positiva. Na maioria dos municípios brasi- } \\
\text { leiros o Fundo de Participação Municipal (FPM) é a principal fonte } \\
\text { de receita. Entretanto, também fazem parte destas transferências } \\
\text { à cota IOF-ouro, cota do IPVA e a cota do ICMS. } \\
\text { Se o efeito positivo das transferências for maior do que o efeito da } \\
\text { renda o fenômeno flypaper é confirmado, sugerindo a presença } \\
\text { de ilusão fiscal. }\end{array}$ \\
\hline Simplicidade fiscal $(\mathrm{S} i)$ & $\begin{array}{l}\text { É medido pelo grau de complexidade fiscal ponderado pelo grau } \\
\text { de visibilidade fiscal. Espera-se uma relação inversa entre a sim- } \\
\text { plicidade e o gasto. } \\
\qquad S i=H H^{*} \text { Grau de visibilidade } \\
\text { Complexidade fiscal } \\
\text { É medida pelo índice Herfindahl }(H H) \text { o qual mede o grau de com- } \\
\text { plexidade fiscal. Quanto maior o valor do índice menor a comple- } \\
\text { xidade, ou seja, menor a dificuldade que contribuinte possui para } \\
\text { compreender o sistema fiscal. } \\
\text { Visibilidade fiscal } \\
\text { É dada pela razão entre impostos diretos e a receita tributária. } \\
\text { Quanto mais visível o sistema fiscal maior a compreensão dos con- } \\
\text { tribuintes sobre a carga tributária. }\end{array}$ \\
\hline Variáveis Sociodemográficas & Descrição \\
\hline Mortalidade infantil & $\begin{array}{l}\text { Número de crianças que não deverão sobreviver ao primeiro ano } \\
\text { de vida em cada } 1000 \text { crianças nascidas vivas. }\end{array}$ \\
\hline Razão de dependência & $\begin{array}{l}\text { Razão de dependência é medida pela razão entre o número de } \\
\text { pessoas com } 14 \text { anos ou menos e de } 65 \text { anos ou mais de idade } \\
\text { (população dependente) e o número de pessoas com idade de } 15 \\
\text { a } 64 \text { anos (população potencialmente ativa) multiplicada por } 100 \text {. }\end{array}$ \\
\hline Taxa de envelhecimento & $\begin{array}{l}\text { Razão entre a população de } 65 \text { anos ou mais de idade e a popula- } \\
\text { ção total multiplicado por } 100 \text {. }\end{array}$ \\
\hline
\end{tabular}


Quadro 1. Descrição das Variáveis. (Continuação)

\begin{tabular}{|l|l|}
\hline Variáveis Sociodemográficas & \multicolumn{1}{c|}{ Descrição } \\
\hline Taxa de atendimento escolar & $\begin{array}{l}\text { Razão entre a população de } 6 \text { a } 14 \text { anos de idade que estava fre- } \\
\text { quentando a escola, em qualquer nível ou série e a população total } \\
\text { nesta faixa etária multiplicado por 100. }\end{array}$ \\
\hline Índice de GINI & $\begin{array}{l}\text { Mede o grau de desigualdade existente na distribuição de indiví- } \\
\text { duos segundo a renda domiciliar per capita. Seu valor varia de 0, } \\
\text { quando não há desigualdade (a renda domiciliar per capita de todos } \\
\text { os indivíduos tem o mesmo valor), a 1, quando a desigualdade é } \\
\text { máxima (apenas um indivíduo detém toda a renda). O universo de } \\
\text { indivíduos é limitado àqueles que vivem em domicílios particulares } \\
\text { permanentes. }\end{array}$ \\
\hline IDHM - Educação & $\begin{array}{l}\text { Índice sintético da dimensão Educação que é um dos } 3 \text { componen- } \\
\text { tes do IDHM. É obtido através da média geométrica do subíndice } \\
\text { de frequência de crianças e jovens à escola, com peso de 2/3, e do } \\
\text { subíndice de escolaridade da população adulta, com peso de 1/3. }\end{array}$ \\
\hline $\begin{array}{l}\text { Dummies para regiões NE; NO; } \\
\text { SE E SUL. }\end{array}$ & $\begin{array}{l}\text { Espera-se captar influência geográfica e cultural dessas regiões } \\
\text { sobre o comportamento gasto público municipal. }\end{array}$ \\
\hline
\end{tabular}

A Tabela 5 mostra as estatísticas descritivas das variáveis analisadas neste trabalho. Observa-se que no ano de 2010 o gasto corrente por pessoa apresenta uma grande flutuação entre os municípios e possui uma média de 1.545 reais. As transferências lump sum por pessoa também apresentam uma elevada flutuação, com valor mínimo de 109,21 e máximo de 8.785,95 reais.

Tabela 5 - Estatísticas Descritivas das Variáveis

\begin{tabular}{|c|c|c|c|c|c|}
\hline Variáveis & Obs. & Média & Desvio Padrão & Mínimo & Máximo \\
\hline \multicolumn{6}{|l|}{ Dependente } \\
\hline Gasto per capita & 5279 & 1545 & 752 & 143 & 17795 \\
\hline \multicolumn{6}{|l|}{ Explicativas } \\
\hline Renda mediana & 5279 & 620 & 170 & 200 & 1800 \\
\hline Tax share & 5279 & 0,7259 & 0,1477 & 0,2754 & 1,2469 \\
\hline População & 5279 & 34292 & 204888 & 805 & $1,13 \mathrm{E}+07$ \\
\hline Simplicidade fiscal & 5279 & 0,1579 & 0,0752 & 0 & 0,8246 \\
\hline Transferências per capita & 5279 & 1116 & 754 & 109 & 8785 \\
\hline Taxa de mortalidade infantil & 5279 & 19 & 7 & 8 & 46 \\
\hline Razão de dependência & 5279 & 51 & 8 & 30 & 118 \\
\hline Taxa de envelhecimento & 5279 & 8,4397 & 2,4221 & 1,4600 & 20 \\
\hline Taxa de atendimento escolar & 5279 & 97,1784 & 2,5599 & 51 & 100 \\
\hline Índice de GINI & 5279 & 0,4934 & 0,0656 & 0,2800 & 0,8000 \\
\hline IDHM - Educação & 5279 & 0,5611 & 0,0926 & 0,2070 & 0,8250 \\
\hline
\end{tabular}

Fonte: elaboração própria. 


\section{Estratégia empírica}

Admitindo os parâmetros de ilusão fiscal definidos acima e aplicando o logaritmo na Equação 16. Temos a seguinte equação a ser estimada:

$$
\begin{gathered}
\ln e_{i}=\ln a+\theta_{1} \ln \frac{b_{m}}{b}+\theta_{2} \operatorname{lnN}_{i}+\beta_{2} \ln y_{i}+\theta_{3} \ln \text { Transferências }_{i} \\
+ \\
+\theta_{4} \ln \text { Simpliciade }_{i}+\sum \beta Z
\end{gathered}
$$

Em que

$$
\theta_{2}=\left(\theta_{1}+1\right)(\lambda-1)
$$

Logo, o grau de congestionamento $(\lambda)$ é dado por:

$$
\lambda=\frac{\left(\theta_{2}+\theta_{1}+1\right)}{\left(\theta_{1}+1\right)}
$$

Para estimação da Equação 20 será utilizada a técnica econométrica de Mínimos Quadrados Ordinários (MQO).

\section{Resultados e discussões}

A Tabela 6.1. apresenta as estimações do modelo de demanda do gasto público local. As estimações apresentadas foram realizadas usando a técnica de Mínimos Quadrados Ordinários (MQO). Nos testes de avaliação dos modelos foi identificado o problema de heterocedasticidade. Desta forma, as estimações foram realizadas com erro padrão robusto.

Na segunda coluna da Tabela 6.1, temos a estimação do modelo sem incorporar as variáveis de ilusão fiscal. Observa-se que a elasticidade-renda é positiva, enquanto que a variável tax share gera um impacto negativo sobre gasto per capita (estas relações permanecem em todas as estimações). Isto corrobora com a teoria na classificação de bens públicos como bens normais. Entretanto, o coeficiente da população possui o sinal negativo. Uma justificativa para esta relação está associada a ganho de escala no fornecimento de bens e serviços 
públicos nas grandes cidades. ${ }^{22}$ Como resultado da combinação dos coeficientes da população e do tax share encontrou-se um grau de congestionamento de 0,60 , o que sugere um grau de publicidade maior do que encontrado na literatura internacional. Os trabalhos seminais de Borcherding e Deacon (1972) e Bergstrom e Goodman (1973) apresentam um grau de congestionamento em torno de 1.

Embora a magnitude dos coeficientes seja diferente, os resultados da coluna 2 apresentam efeitos comparáveis aos encontrados por Mendes e Sousa (2006) e Meneses, Saiani e Zoghbi (2011), ${ }^{23}$ os quais estimaram a mesma função para o Brasil com dados do censo de 2000. No trabalho de Mendes e Sousa (2006) o grau de congestionamento encontrado foi de 0,7 e no trabalho de Meneses, Saiani e Zoghbi (2011) foi de 0.57.

Nas colunas 3, 4 e 5 da Tabela 6 estão descritas as estimações de modelos com a incorporação de variáveis que buscam captar os efeitos da ilusão fiscal sobre o gasto público local. Na coluna 3 é incorporada apenas a variável de simplicidade fiscal. Observam-se, nesta coluna, que os resultados gerais não são muitos diferentes da estimação do modelo sem a variável de ilusão. Entretanto, o coeficiente da variável simplicidade é estatisticamente significativo e possui o sinal esperado. Desta forma, um aumento no grau de simplicidade do sistema tributário reduz o gasto público local. O resultado corrobora a formalização teórica de que a baixa complexidade da receita e visibilidade do sistema tributário induz a redução do gasto público.

\footnotetext{
${ }^{22}$ Ver Oates (1988), Edwards (1990), Means e Mehay (1995), e Reiter e Weichenrieder (1997).

${ }^{23}$ Estes trabalhos utilizam variáveis controles diferentes das usadas aqui. Nos trabalhos citados não há preocupação com a existência de ilusão fiscal, assim, eles não incorporam variáveis que possam captar os seus possíveis efeitos sobre o gasto público.
} 
Tabela 6 - Estimações do modelo de demanda por gasto público local

\begin{tabular}{|c|c|c|c|c|}
\hline Variáveis Explicativas (em logaritmo) & Modelo 1 & Modelo 2 & Modelo 3 & Modelo 4 \\
\hline Renda mediana & $0,6653^{* * *}$ & $0,6671^{* * *}$ & $0,2028^{* * *}$ & $0,2051^{* * *}$ \\
\hline Tax share & $-0,4182^{* * *}$ & $-0,4355^{\star * *}$ & $-0,0627^{\star \star *}$ & $-0,0712^{* * *}$ \\
\hline População & $-0,2325^{* * *}$ & $-0,2284^{* * *}$ & $0,0639^{* * *}$ & $0,0644^{\star \star \star}$ \\
\hline Simplicidade Fiscal & $-\cdots-\cdot$ & $-0,0414^{\star \star *}$ & $-\cdots--$ & $-0,0173^{\star \star *}$ \\
\hline Transferências per capita & $\ldots$. & ---- & $0,7327^{\star * *}$ & $0,7299^{* * *}$ \\
\hline Constante & $4,1893^{\star \star *}$ & $4,0303^{* * *}$ & $-1,9895^{\star * \star}$ & $-2,0226^{\star * *}$ \\
\hline Variáveis sociodemográficas & Sim & Sim & Sim & Sim \\
\hline Dummies regionais & Sim & Sim & Sim & Sim \\
\hline Congestionamento & 0,6003 & 0,5952 & 1,0681 & 1,0693 \\
\hline N & 5279 & 5278 & 5279 & 5278 \\
\hline r2 & 0,5056 & 0,5102 & 0,7974 & 0,7982 \\
\hline r2_a & 0,5044 & 0,5089 & 0,7969 & 0,7977 \\
\hline BIC & 1235 & 1195 & -3465 & -3478 \\
\hline AIC & 1143 & 1097 & -3564 & -3583 \\
\hline
\end{tabular}

Nota: $\left({ }^{*}\right),\left({ }^{* *}\right)$ e $\left({ }^{* * *}\right)$ representam o nível de significância do coeficiente, respectivamente, em $10 \%, 5 \%$ e $1 \%$.

Fonte: elaboração própria a partir dos dados da pesquisa.

Na coluna 4 (Tabela 6) é incorporada ao modelo apenas a variável transferência lump sum per capita, com objetivo de identificar o efeito flypaper. Os resultados, se comparados ao modelo inicial, sofrem uma grande mudança. Com relação às variáveis, temos que a magnitude da elasticidade-renda e do coeficiente do tax share sofre uma grande redução, mas esses coeficientes permanecem estatisticamente significativos. O coeficiente da variável população além de ser menor também apresenta um efeito positivo. Desta forma, os possíveis ganhos de escala associado ao tamanho da população deixam de existir dado o efeito das transferências per capita sobre o gasto.

Os resultados nas colunas 4 e 5 demonstram que o gasto público local é mais sensível a variações nas transferências do que a variações na renda da população. Este resultado implica uma evidência empírica do efeito flypaper. Desta forma, ratificamos que as transferências 
lump sum no Brasil distorcem a percepção dos indivíduos sobre o preço do imposto e favorece a ampliação do gasto público local.

O financiamento do gasto público local através das transferências do tipo lump sum reduz a ligação entre o pagamento de impostos e o recebimento de bens e serviços. Esta desconexão claramente reduz a percepção dos eleitores sobre o custo dos bens e serviços ofertados pelo governo local. A menor percepção dos custos, por parte dos contribuintes, permite ao governo local expandir os gastos. Desta forma, com expansão dos gastos e sem perceber os custos reais, o eleitor acredita que houve uma redução na quantidade ou preço dos impostos que ele paga. Assim, a existência do efeito flypaper é uma importante evidência do fenômeno de ilusão fiscal presente na estrutura de financiamento dos gastos locais no Brasil.

O grau de congestionamento de 1,06 descrito nas estimaçóes das colunas 4 e 5 indica que os bens e serviços ofertados apresentam apenas características de bens privados. Este resultado é semelhante aos resultados encontrados nos trabalhos Borcherding e Deacon (1972); Bergstrom e Goodman (1973); Mcmilam (1987); Heyndels e Smolders (1994); Binet (2012) entre outros.

Com relação ao efeito positivo do tamanho da população sobre o gasto público local, há uma ampla literatura que defende que nas grandes cidades os custos para oferta de bens e serviços públicos são maiores. ${ }^{24}$ Estes custos estão associados a problemas sociais como elevadas taxas de criminalidade e maior desigualdade de renda; e também podem estar associados a uma maior dimensão administrativa com elevada burocracia.

Com relação às variáveis sociodemográficas, destacamos o efeito do Índice de Gini que em todos os modelos estimados apresentou um coeficiente positivo e estatisticamente significativo. Este resultado confirma a hipótese de que quanto maior desigualdade de renda, maior será o tamanho do governo (gasto governamental). Esta hipótese foi formulada por Meltzer e Richard (1981), que argumentam que à medida que aumenta a concentração de renda a escolha do eleitor mediano se aproxima da população mais pobre, a qual demanda uma quantidade maior de políticas sociais e redistributivas, e consequentemente maiores gastos públicos.

${ }^{24}$ Ver Alesina et al. (2000); Borge e Ratts (2004); Nellor (1984); Glaeser e Sacerdote (1999). 
Na Tabela 7, reestimamos os modelos 1 e 4 para duas subamostra. A primeira com municípios de população inferior a 50 mil habitantes (colunas 2 e 3) e a segunda com municípios com mais de 50 mil habitantes (colunas 4 e 5). Foi novamente utilizada à técnica de Mínimos Quadrados Ordinários. Os testes de avaliação do modelo apontaram para problemas de heterocedasticidade, desta forma, as estimações foram realizadas com erro padrão robusto.

Tabela 7 - Estimações do modelo de demanda do gasto público local para subgrupos de municípios

\begin{tabular}{|c|c|c|c|c|}
\hline \multirow[b]{2}{*}{ Variáveis Explicativas (em logaritmo) } & \multicolumn{2}{|c|}{$\begin{array}{l}\text { Municípios com até } \\
50 \text { mil habitantes }\end{array}$} & \multicolumn{2}{|c|}{$\begin{array}{l}\text { Municípios com mais de } \\
50 \text { mil habitantes }\end{array}$} \\
\hline & Modelo 1 & Modelo 4 & Modelo 1 & Modelo 4 \\
\hline Renda mediana & $0,5234^{* \star *}$ & $0,1555^{\star * *}$ & $1,1399^{* * *}$ & $0,5255^{* * *}$ \\
\hline Tax share & $-0,3216^{\star \star *}$ & $-0,0612^{\star \star \star}$ & $-0,3832^{\star \star \star}$ & $-0,1377^{*}$ \\
\hline População & $-0,3088^{* * *}$ & $0,0548^{\star * *}$ & $-0,0487^{\star \star *}$ & $0,0617^{\star \star *}$ \\
\hline Simplicidade Fiscal & & $-0,0142^{\star *}$ & & $-0,0500^{*}$ \\
\hline Transferências per capita & & $0,7387^{* * *}$ & & $0,5723^{\star * *}$ \\
\hline Constante & $6,4372^{\star \star \star}$ & $-1,2359^{*}$ & $-11,3118^{\star \star \star}$ & $-7,9986^{\star * \star}$ \\
\hline Variáveis sociodemográficas & Sim & Sim & Sim & Sim \\
\hline Dummies regionais & Sim & Sim & Sim & Sim \\
\hline Congestionamento & 0,5448 & 1,0583 & 0,9210 & 1,0731 \\
\hline $\mathrm{N}$ & 4696 & 4695 & 583 & 583 \\
\hline r2 & 0,5753 & 0,8133 & 0,4346 & 0,6882 \\
\hline r2_a & 0,5741 & 0,8127 & 0,4217 & 0,6885 \\
\hline BIC & 246 & -35895 & 279 & -60 \\
\hline AIC & 156 & -3699 & 218 & -126 \\
\hline
\end{tabular}

Nota: $\left({ }^{*}\right),\left({ }^{* *}\right)$ e $\left({ }^{* * *}\right)$ representam o nível de significância do coeficiente, respectivamente, em $10 \%, 5 \%$ e $1 \%$.

Fonte: elaboração própria a partir dos dados da pesquisa.

Nas colunas 2 e 4 estão especificados os modelos sem as variáveis de ilusão fiscal. Com relação ao modelo da coluna 2, os resultados são equivalentes aos apresentados anteriormente, mas com mudanças na magnitude dos coeficientes. Na coluna 4 podemos observar importantes mudanças nos resultados. Primeiro o grau de congestionamento é de 0,92 , diferentemente do resultado anterior os ganhos de 
escala para estes municípios é bem reduzido. Segundo, observa-se a caracterização dos bens públicos locais providos pelo setor público, nos municípios com mais de 50 mil habitantes, como bens de luxo, uma vez que a elasticidade renda é maior do que l. Este resultado pode ser justificado por que nas grandes cidades além dos bens meritórios (educação e saúde), os municípios ainda ofertam um conjunto de bens e serviços que apresentam as características de bens superiores, por exemplo: a manutenção de parques (áreas de lazer) e a infraestrutura urbana de grandes avenidas.

No modelo com as variáveis de ilusão fiscal (coluna 3) há uma forte redução no coeficiente que mede elasticidade-renda. Como o efeito das transferências permanece elevado, temos uma ampliação do efeito flypaper para os municípios com menos de 50 mil habitantes. Também se observa uma grande redução do efeito da simplicidade fiscal sobre o gasto público nesses municípios.

Como foi descrito na seção 2 , nos municípios com população até 50 mil habitantes a receita própria representa pouco mais de $11 \%$ da receita corrente total e em $96 \%$ destes municípios a receita do FPM é maior do que a receita tributária. Estas características são importantes para compreender redução do efeito da simplicidade fiscal e a elevação no efeito flypaper neste grupo de municípios. Ou seja, como eles são mais dependentes de transferências, maior será o efeito flypaper e à medida que receita própria perde importância relativa no financiamento do gasto, menor serão os efeitos da simplicidade da estrutura tributária.

Para subamostra com municípios que possuem mais de 50 mil habitantes, no modelo com as variáveis de ilusão fiscal (coluna 5), há uma forte redução no coeficiente que mede elasticidade-renda. Esse resultado sugere que a elasticidade renda maior do que 1 (verificada nos modelos sem variáveis de ilusão fiscal) pode está sendo originada de um erro de especificação. Temos que o coeficiente da simplicidade fiscal é estatisticamente significativo e a sensibilidade do gasto, em relação ao grau de simplicidade fiscal, é muito maior nestes municípios do que dos municípios menores. Por outro lado, a elasticidade do gasto com relação às transferências lump sum é menor. Portanto, para os municípios maiores o efeito flypaper, comparado aos resultados anteriores, é bem reduzido. 
As transferências do tipo lump sum são justificadas, na maior parte dos casos, por desequilíbrios fiscais verticais. No Brasil, a regra de redistribuição destas transferências favorece os municípios menores. Desta forma, os municípios menores podem ampliar os gastos sem necessariamente aumentar os níveis arrecadação. Por sua vez, os municípios maiores precisam de mais criatividade para o financiamento dos gastos. Isto justifica, em parte, os efeitos distintos da simplicidade fiscal e das transferências lump sum nestes dois grupos de municípios.

\section{Considerações finais}

Este trabalho partiu da observação de que a estrutura de financiamento do gasto público municipal no Brasil favorece o surgimento e a exploração de ilusão fiscal. Os testes empíricos realizados confirmaram que a magnitude do gasto público local é influenciada pela presença de mecanismos geradores de ilusão fiscal. Mais especificamente, o estudo encontrou evidências de que quanto maior a participação de transferências lump sum na receita municipal e/ou quanto mais complexo e menos visível a tributação maior será o gasto público local.

Estes resultados corroboram a análise de Silva e Siqueira (2014), que encontra uma relação positiva entre o gasto do governo federal no Brasil e o grau de visibilidade da arrecadação tributária. Eles também são consistentes com as evidências obtidas por Mendes (2005) de que parte das transferências fiscais recebidas pelos municípios é capturada por grupos de interesse, e de que o grau de captura é maior quanto maior a participação das transferências no financiamento do gasto público local.

Portanto, as evidências empíricas para Brasil indicam que, como prever a teoria, ilusão fiscal não só afeta o nível do gasto governamental, mas também facilita o gasto improdutivo e atividades de rent-see$k i n g$. Isto aponta para a necessidade de incluir o problema da ilusão fiscal no debate sobre políticas relacionadas ao controle e à qualidade do gasto público. Em particular, os resultados deste artigo ressaltam a importância de estimular o financiamento dos governos municipais através de tributos locais, com foco naqueles mais simples e transpa- 
rentes, e, ao mesmo tempo, reduzir a participação de transferências lump sum.

É interessante investigar também a capacidade de aperfeiçoamentos no marco regulatório - como a instituição da Lei de Responsabilidade Fiscal (LRF) - de reduzir os incentivos para a expansão do gasto público improdutivo, mesmo na presença de ilusão fiscal. Neste sentido, são necessários novos estudos, baseados em um painel de dados municipais. ${ }^{25}$

\section{Referências}

ABIZADEH, Sohrab; YOUSEFI, Mahmood. An empirical re-examination of Wagner's law. Economics Letters, v. 26, n. 2, p. 169-173, 1988.

AFONSO, José Roberto Rodrigues; SOARES, Julia Morais; DE CASTRO, Kleber Pacheco. Avaliação da estrutura e do desempenho do sistema tributário brasileiro: Livro branco da tributação Brasileira. Inter-American Development Bank, 2013.

AFONSO, José Roberto Rodrigues; ARAÚJO, Érika Amorim. A capacidade de gasto dos municípios brasileiros: arrecadação própria e receita disponível. BNDES, Rio de Janeiro, 2001.

ALESINA, Alberto et al. Redistributive public employment. Journal of Urban Economics, v. 48, n. 2, p. 219-241, 2000.

BERGSTROM, Theodore C and GOODMAN, Robert P. Private Demands for Public Goods. The American Economic Review, Vol. 63, No. 3 pp. 280-296, 1973.

BIRD, Richard M. Wagner's o Law of Expanding State Activity. Public Finance, v. 26, n. 1, p. 1-26, 1971.

BORCHERDING, Thomas E. and DEACON, Robert T. The Demand for the Services of Non-Federal Governments. The American Economic Review, Vol. 62, No. 5, pp. 891-901, 1972.

BORCHERDING, Thomas E. The causes of government expenditure growth: A survey of the US evidence. Journal of Public Economics, v. 28, n. 3, p. 359-382, 1985.

BORGE, Lars-Erik; RATTS, Jorn. Income distribution and tax structure: Empirical test of the MeltzerRichard hypothesis. European Economic Review, v. 48, n. 4, p. 805-826, 2004.

BUCHANAN, J. and TULLOCK, G. The Calculus of Consent, Ann Arbor, University of Michigan Press, 1962.

BUCHANAN, James. Public finance in democratic process : fiscal institutions and individual choice. Chapel Hill : University of North Carolina Press, 1967.

BUCHANAN, James M. and WAGNER, Richard E. Democracy in deficit: The political legacy of Lord Keynes. New York, 1977.

COSSIO, Fernando Andrés Blanco; CARVALHO, LM. Os efeitos expansivos das transferências intergovernamentais e transbordamentos espaciais das despesas públicas: evidências para os municípios brasileiros-1996. Pesquisa e Planejamento Econômico, v. 31, n. 1, p. 31, 2001.

\footnotetext{
25 Note que o estudo de Mendes (2005) usou dados municipais referentes ao ano de 1996, portanto,
} anterior à LRF, e este artigo trabalha com dados municipais de corte transversal. 
DIAMOND, Jack. A note on the public choice approach to the growth in government expenditure. Public Finance Review, v. 17, n. 4, p. 445-461, 1989.

DOLLERY, Brian E.; WORTHINGTON, Andrew C. The empirical analysis of fiscal illusion. Journal of Economic Surveys, v. 10, n. 3, p. 261-297, 1996.

DOLLERY, Brian; WORTHINGTON, Andrew. Fiscal illusion at the local level: an empirical test using Australian municipal data. Economic Record, v. 75, n. 1, p. 37-48, 1999.

DELL'ANNO, Roberto and MOURÃO, Paulo. Fiscal Illusion around the World: An Analysis Using the Structural Equation Approach. Public Finance Review, pp. 270-301, 2012.

DOWNS, Anthony. An Economic Theory of Democracy. New York: Harper and Row, 1957.

DOWNS, Anthony. Why the Government Budget is Too Small in a Democracy. World Politics, Vol. 12, No. 4, pp. 541-563, 1960.

GEMMELL, Norman. Wagner's Law and Musgrave's Hypotheses. The Growth of the Public Sector. Edward Elgar, Aldershot, p. 103-20, 1993.

GEMMELL, Norman; MORRISSEY, Oliver; PINAR, Abuzer. Fiscal illusion and the demand for government expenditures in the UK. European Journal of Political Economy, v. 15, n. 4, p. 687-704, 1999.

GEMMELL, Norman; MORRISSEY, Oliver; PINAR, Abuzer. Fiscal illusion and political accountability: theory and evidence from two local tax regimes in Britain. Public Choice, v. 110, n. 3-4, p. 199-224, 2002.

GUEDES, Kelly Pereira; GASPARINI, Carlos Eduardo. Descentralização fiscal e tamanho do governo no Brasil. Economia Aplicada, v. 11, n. 2, p. 303-323, 2013.

HEYNDELS, Bruno; SMOLDERS, Carine. Tax complexity and fiscal illusion. Public Choice, v. 85, n. 1-2, p. 127-141, 1995.

LAMARTINA, Serena; ZAGHINI, Andrea. Increasing Public Expenditure: Wagner's Law in OECD Countries. German Economic Review, v. 12, n. 2, p. 149-164, 2011.

MATTOS, Enlinson; ROCHA, Fabiana; ARVATE, Paulo. Flypaper effect revisited: evidence for tax collection efficiency in Brazilian municipalities. Estudos Econômicos, v. 41, n. 2, p. 239-267, 2011.

MELTZER, Allan H.; RICHARD, Scott F. A rational theory of the size of government. Journal of Political Economy, v.89, n.5, p.914-928, 1981.

MENDES, Marcos. Capture of fiscal transfers: a study of Brazilian local governments. Economia aplicada, v. 9, n. 3, p. 427-444, 2005.

MENDES, Constantino Cronemberger; SOUSA, Maria da Conceição Sampaio. Estimando a demanda por serviços públicos nos municípios brasileiros. Revista Brasileira de Economia, v. 60, n. 3, p. 281-296, 2006.

MENEZES, Rafael Terra de; SAIANI, Carlos César Santejo; ZOGHBI, Ana Carolina Pereira. Demanda mediana por serviços públicos e desempenho eleitoral: evidências do modelo do eleitor mediano para os municípios brasileiros. Estudos Econômicos, v. 41, n. 1, p. 25-57, 2011.

OATES, Wallace E. On the Nature and Measurement of Fiscal Illusion: A Survey. In Taxation and Fiscal Federalism: Essays in Honour of Russell Mathews, edited by G. Brennan et al., p. 65-82. Sydney: Australian National University Press, 1988.

POMMEREHNE, Werner W. and SCHNEIDER, Friedrich. Fiscal illusion, political institutions, and local public spending. Kyklos, v. 31, n. 3, p. 381-408, 1978.

RODDEN, Jonathan "Reviving Leviathan: Fiscal Federalism and the Growth of Government". International Organization 57, Fall 2003, pp. 695-729.

SAKURAI. S. N. 'Efeitos assimétricos das transferências governamentais sobre os gastos públicos locais: evidências em painel para os municípios brasileiros', Pesquisa e Planejamento Econômico, Vol. 43, No. 2, 2013. 
SHELTON, Cameron A. The size and composition of government expenditure. Journal of Public Economics, v. 91, n. 11, p. 2230-2260, 2007.

SILVA, A. M. A \& SIQUEIRA, R. B. Demanda por gasto público no Brasil no período pós-redemocratização: Testes da lei de Wagner e da hipótese de Mill de ilusão fiscal. Pesquisa e Planejamento Econômico, n. 43, 2014.

SIQUEIRA, R. B \& NOGUEIRA J R. Taxation, inequality, and the illusion of the social contract in Brazil. World Economics Association Conferences - Is a more inclusive and sustainable development possible in Brazil? n. 1: $5^{\text {th }}$ May $-20^{\text {th }}$ July, 2014.

STEIN, Ernesto. Fiscal Decentralization and Government Size in Latin America. Journal of Applied Economics 2 (2):357-91, 1999.

REZENDE, Fernando. A reforma esquecida: orçamento, gestão pública e desenvolvimento. Rio de Janeiro: Editora FGV, 2013.

Tanzi, V. Government versus Market: The Changing Economic Role of the State, Cambridge: Cambridge University Press, 2011.

VARSANO, R. et al. Uma análise da carga tributária no Brasil. Brasília: Ipea, 1998.

WAGNER, Richard. Revenue Structure, Fiscal Illusion and Budgetary Choice. Public Choice, No. 25, pp. 45-61, 1976. 